authorities that the labs must be supplied in a different way, and I think that the people here begin to recognise that the system of supply must be altered for the scientific institutions. But, at present, if for instance we require four bars of phosphor bronze, the need of which we had not anticipated in the beginning of the year, we must get it as an exception and the permission of the sub-secretary of the Heavy Industries is required and this means a lot of correspondence, which is equally extensive if we require 10 kilograms, 10 tons or 10 loads of stuff. And so even if the Institute is given sufficient money, and even if the industries are quite decent, we are actually very badly supplied.

He believed, however, that things would get better. But later he wrote:

My colleagues the scientists are very scared of me and behave like pigs. My institute is attached to the Academy of Science, of which I am not a member but they govern my institute. The president is Karpinsky, he is ninety years old. During meetings of the Council he sleeps with a happy and kind smile on his face.

It is for insights such as these, showing the reactions to Soviet bureaucracy of a great man who had experienced Cambridge, that I recommend this book. Parts of it are compulsive reading. How much the bureaucracy has changed since then is not discussed but in any case Kapitza came to terms with it, became a Hero of Socialist Labour, received several Orders of Lenin and was throughout a sane and courageous voice in Soviet science. One wonders if he would have survived the early days without Rutherford's moral support, and Rutherford's efforts - though unsuccessful - to secure his release, which are here described by Badash. Kapitza repaid some of his debt in his "Recollections of Lord Rutherford", published in the Proceedings of the Royal Society in 1966.

Kapitza, then, was back to work by 1936. The author remarks that the timing was fortunate, for Rutherford, upon whom he depended so much for aid and encouragement, died in October 1937.

Sir Nevill Mott is Emeritus Professor of Physics at the University of Cambridge.
Arrhenius and Mittag-Leffler intervened rather irregularly, but whenever they felt moved to support a personal preference, or to thwart the candidate of a rival, they acted with rare zest.

In this running confrontation, Arrhenius had a notable early success when he saw to it that the first prize in chemistry went to J.H. van't Hoff, whose work on electrolytic phenomena complemented his

\section{Between machination and merit}

\section{Robert Fox}

The Beginnings of the Nobel Institution: The Science Prizes, 1901-1915.

By Elisabeth Crawford.

Cambridge University Press: 1985.

Pp.281. f22.50, \$34.50.

A FEW days after Alfred Nobel's death in December 1896, his close relatives gathered expectantly for the reading of his will. They were in for a shock. For Nobel had bequeathed to his family a mere one million crowns. The rest of his vast estate, amounting to 30 times that amount (over $£ 1 \frac{1 / 2}{2}$ million), was to be invested to provide five annual prizes, for physics, chemistry, medicine or physiology, literature, and what Nobel (a convinced pacifist, despite the fortune he had made from explosives) called "contributions to the fraternity between nations". Predictably, the will was contested. But the adjustment that was made in favour of the family was meagre, and in 1901 the first prizes were awarded essentially in accordance with Nobel's wishes.

Elisabeth Crawford traces the difficult birth of the Nobel system and the labyrinthine processes by which the awards were made in physics and chemistry between 1901 and 1915. The sheer size of the prizes, each of them worth about 30 times the annual salary of a university professor, was enough to ensure intense public interest. And the element of spectacle was further enhanced by national as well as personal rivalries which made it difficult for the brash newcomer to integrate with the rather chaste rèward system of European science as it existed at the beginning of the century. Tradition demanded, of course, that the cruder rivalries should be concealed. But Crawford penetrates this facade to excellent effect. Drawing on her intimate knowledge of the relevant Nobel archives (open since 1974, in accordance with a new 50-year rule) and of the context and content of Swedish science in the early twentieth century, she casts radically new light on the complex interaction between the dispersed international networks of nominators and the subject committees in Sweden.

Few readers will be surprised by Crawford's demonstration of the keen opposition between the various national traditions in science, for, by 1900 , science was emerging as a battle-field on which the European powers were only too ready to try their strength, not least with the disturbing new force in research, the United States. The French, it seems, were especially prone to nominate their fellowcountrymen, far more so than the Germans, who have a commendably low score on Crawford's ingenious index of chauvinism. (Britain's record was mixed, with the physicists appearing distinctly more chauvinistic than the chemists.) However, Crawford's evidence suggests that it was the Swedes themselves who injected the greatest element of competitiveness. Here, the main antagonists were Svante Arrhenius, already distinguished internationally for his work on the theory of solutions, and the mathematician Gösta Mittag-Leffler. The two men were poles apart in their political sympathies and in temperament and lifestyle. Arrhenius was liberal, popular and modest to the point of insecurity about his scientific abilities, whereas Mittag-Leffler was conservative, flamboyant and more respected than liked. As Crawford shows,

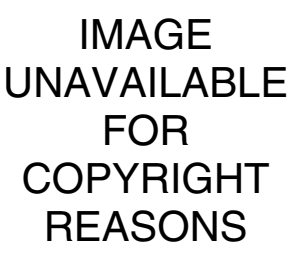

Arrhenius - "modest to the point of insecurity about his scientific abilities...".

own. In 1909, Arrhenius successfully backed another ionist, Wilhelm Ostwald, and; using more negative tactics, he managed to delay an award for his rival Walther Nernst until 1921 (15 years after the first nominations for Nernst had been received). Mittag-Leffler, by contrast, saw his main mission as the advancement of mathematical physics. It was he who secured at least a share in the physics prize for H.A. Lorentz in 1902. And it was only misfortune which denied him his greatest triumph: his long campaign in favour of Poincaré had still not succeeded when Poincaré died in 1912.

These episodes and the intolerance they imply are far from edifying. But generally Crawford's book is reassuring. It provides ample evidence that although animosity, national interest and the stage-managing of nominations all played their part, scientific merit was nevertheless consistently rewarded. It is arguable that a blunder was made in 1908, when the French experimentalist Gabriel Lippmann emerged as a successful compromise candidate, following MittagLeffler's mishandling of his own campaign in favour of a joint award to Planck and Wien. But while Lippmann was no Planck, even this decision rewarded excellence of a kind. Like the overwhelming majority of the decisions discussed by Crawford, it seems a beacon of wisdom when compared, say, with the award of the first prize in literature to the poet Sully Prudhomme as a sop to French pride. All told, the physicists and chemists of Europe and North America come out of this intriguing and well-told story with a good deal of credit. $\square$

Robert Fox is British Academy Reader in the Humanities at the University of Lancaster. 